\title{
An emerging and growing problem
}

\author{
Um problema emergente e crescente
}

\author{
Francisco Cardoso
}

\section{MD, PhD; Serviço de Neurologia, Departamento de Clínica \\ Médica, Faculdade de Medicina, Universidade Federal de Minas Gerais (UFMG), Belo Horizonte MG, Brazil. \\ Correspondence: \\ Francisco Cardoso Avenida Pasteur 89/1.107 \\ 30150-290 Belo Horizonte MG - Brasil \\ E-mail cardosofe@terra.com.br}

\section{Conflict of interest}

There is no conflict of interest to declare.

Received 01 May 2012

Accepted 08 May 2012
$\mathrm{T}$ he vast amount of work produced by David Marsden, Stanley Fahn, and many other investigators in the 1980s and 1990s established the movement disorders as one of the most active and exciting contemporary areas of Neurology. Since its inception in the $19^{\text {th }}$ century, thanks to the groundbreaking contribution of Jean Martin Charcot, William Gowers, Sir William Osler, among others, this area has been perceived as the realm of chronic and relentlessly progressive disorders, whose care is provided in the setting of outpatient clinics. Recently, there is a growing understand that movement disorders may present with acute problems warranting visits to the emergency rooms. Thus, the comprehensive review of Munhoz et al. on movement disorders emergencies in the current issue of Arquivos de Neuropsiquiatria is timely. The authors tackled etiology, clinical features, and management of a vast gamut of emergencies in patients with movement disorders.

In addition to clinical problems related to hyperkinetic and hypokinetic movement disorders in adults reviewed by the authors, there are two issues that should receive the attention of neurologists interested in this field. At least $8 \%$ of patients with Parkinson's Disease (PD) and a small, but growing number, of individuals with tremor, dystonia, and other hyperkinetic disorders fail to respond to clinical management. With new advances in functional surgery, many of these subjects are candidates for deep brain stimulation (DBS).

As recently reviewed by Morishita et al. ${ }^{2}$, more postoperative urgencies and emergencies have emerged. The authors have separated the scenarios into surgery/procedure related (intracranial hemorrhage, dyskinetic storm, postoperative behavioral and cognitive problems, suicide attempt or ideation, others), hardware related (hardware infection, hardware malfunction, lead migration, and lead misplacement), stimulation-induced difficulties (motor or non-motor symptoms), and others. Given their complexity, patients with these movement disorders emergencies should be referred to units where there is a staff comprising neurologists and neurosurgeons experienced with DBS. The second issue is related to pediatric movement disorders. In comparison to adult patients, much less has been published about emergencies in this population. However, a recent review by Kirkham et al. sheds light on this topic ${ }^{3}$. They described 52 patients, and three groups were recognized: psychogenic disorders $(n=12)$, typically $>10$ years-old, more likely to be female and to have tremor and myoclonus ${ }^{2}$. Inflammatory or autoimmune disorders ( $\mathrm{n}=22)$, including $\mathrm{N}$-methyl-d-aspartate receptor encephalitis, opsoclonusmyoclonus, Sydenham's chorea, systemic lupus erythematosus, acute necrotizing encephalopathy, and other encephalitis and ${ }^{3}$ non-inflammatory disorders $(n=18)$, including drug-induced movement disorder, postpump chorea, metabolic, e.g. glutaric aciduria, and vascular disease, e.g. moyamoya. It noteworthy that, unlike series with adult subjects, there was a significant representation of the psychogenic movement disorders.

To understand the relevance of the issues discussed by Munhoz et al., it is warranted to discuss some epidemiological aspects of movement disorders emergencies. Despite the scarcity of data, there is some information available in the literature, which may help us to understand how frequent movement disorders emergencies are. Yoon et al. ${ }^{4}$, prospectively, evaluated all cases with movement disorders emergencies seen in the emergency room (ER) of a university hospital in South Korea, over a 12-month period of time. They reported that movement disorders accounted just for 58 (0.09\%) of 60,002 visits. Regarding clinical features, the most common clinical presentation was gait disorder ( $\mathrm{n}=21 ; 36.2 \%)$, followed by myoclonus $(16 ; 27.6 \%)$, dystonia (10; $17.2 \%)$, tremor $(8 ; 13.8 \%)$, and acute akinetic crisis $(3 ; 5.2 \%)$. 
As to etiology, drug-induced movement disorders were responsible for more than half $(63.8 \%)$ of cases. It is possible that these figures vary according to some factors, such as organization of the health system, level of the care (e.g., primary versus tertiary), genetic background and others influence the referral pattern. For instance, in an investigation in northern England Woodford and Walker found that Parkinson's disease (PD) was responsible for 12 (4.9\%) of 246 ER admissions to a district general hospital over a 4-year period $^{5}$. One important finding of this study is the increased likelihood of PD patients who went to ER to require nursing home placement. Although the latter also varies according to different geogrphic locations, the data is striking in showing that these individuals are fragile enough to require a more intensive care. In this study, infections, cardiovascular diseases, falls, reduced mobility, and psychiatric complications accounted for the majority of admissions. Another example of how use of ERs varies depending on the geographic location is the study of Klein et al. ${ }^{6}$. These authors studied the reasons for admission of PD patients to a Neurological Department of an academic institution in Israel over a 6-year period of time. Out of 1920 admissions, 143 (7.4\%) were PD patients. Not surpisingly, the reasons for admission in this academic tertiary setting differ from those described in primary care facilities ${ }^{5}$ : motor complications were diagnosed in $37 \%$, psychosis in $24 \%$, general medical problems in $14 \%$, and a combination of motor and psychiatric in $25 \%$ of admissions. In spite of the wide range of numbers ( 0.09 to $7.4 \%$ ) of visits to ER accounted for by patients with movement disorders, one may just expect that they will increase with time. Because of the increased risk of developing PD with ageing and the changes of demographic structure in the most populous nations, it has been estimated that the number of individuals with PD over age 50 in these countries was between 4.1 and 4.6 million in 2005 and will double to between 8.7 and 9.3 million by $2030^{7}$. Considering the Brazilian situation where the country undergoes a process of rapid ageing of the population, the authors of this report concluded that the number of PD patients in 2030 will be more than $100 \%$ than in 2005 . Based on our study of prevalence of PD, one may estimate that there are at least 200.000 PD patients in 2012 in Brazil ${ }^{8}$. If the study of Dorsey et al. ${ }^{7}$ is correct, this figure will exceed 400.000 patients in 2030. The implication is that there will certainly be a growing number of PD patients admitted to ERs over the next decades. This conclusion emphasizes the importance of clinicians becoming familiar with the concepts reviewed by Munhoz and colleagues et al. ${ }^{1}$.

\section{References}

1. Munhoz RP, Moscovich M, Araujo PD, Teive HAG. Movement disorders emergencies: A review. Arq Neuropsiquiatr 2012;70:453-461.

2. Morishita T, Foote KD, Burdick AP, et al. Identification and management of deep brain stimulation intra- and postoperative urgencies and emergencies. Parkinsonism Relat Disord 2010;16:153-162

3. Kirkham FJ, Haywood P, Kashyape P, et al. Movement disorder emergencies in childhood. Eur J Paediatr Neurol 2011;15:390-404.

4. Yoon JH, Lee PH, Yong SW, Park HY, Lim TS, Choi JY. Movement disorders at a university hospital emergency room. An analysis of clinical pattern and etiology.J Neurol 2008;255:745-749.
5. Woodford H, Walker R. Emergency hospital admissions in idiopathic Parkinson's disease. Mov Disord 2005;20:1104-1108.

6. Klein C, Prokhorov T, Miniovitz A, Dobronevsky E, Rabey JM. Admission of Parkinsonian patients to a neurological ward in a community hospital.J Neural Transm 2009;116:1509-1512.

7. Dorsey ER, Constantinescu R, Thompson JP, et al. Projected number of people with Parkinson disease in the most populous nations, 2005 through 2030. Neurology 2007;68:384-386.

8. Barbosa MT, Caramelli P, Maia DP, et al. Parkinsonism and Parkinson's disease in the elderly: a community-based survey in Brazil (the Bambui study). Mov Disord 2006;21:800-808. 